\title{
Gambaran peri-implantitis pada CBCT (Cone-Beam Computed Tomography)
}

\author{
Indra Gunawan ${ }^{1 *}$, Farina Pramanik ${ }^{2}$
}

\section{ABSTRACT}

Objectives: This paper is aimed to report a case of peri-implantitis which is diagnosed using CBCT.

Case Report: A 61 year old male was referred to a dental radiology unit for CBCT examination. The patient complained of pain in the area of the tooth where the implant was attached. CBCT results show there is inflammation around the implant that has been inserted, characterized by a visible radiolucent area in 1/3 of the cervical implant on the mesial, distal, buccal / labial and palatal sides with varying

Keywords: $C B C T$, peri-implantitis

Cite this article: Gunawan I, Pramanik F. Gambaran peri-implantitis pada CBCT (Cone-Beam Computed Tomography). Jurnal Radiologi Dentomaksilofasial Indonesia 2020;4(3)83-90. https://doi.org/10.32793/jrdi.v4i3.586

\section{PENDAHULUAN}

Saat ini, peri-implantitis didefinisikan sebagai suatu kondisi patologis yang terjadi pada jaringan $\mathrm{d}$ sekitar implan gigi, yang memiliki tanda berupa peradangan pada jaringan periimplan dan hilangnya tulang pendukung secara progresif. ${ }^{1-5}$ Penegakan diagnosis peri-implantitis yang tepat sangat penting sehingga membutuhkan cara yang tepat dalam melakukannya. Kunci dari penentuan diagnosis peri -implantitis merupakan perbandingan dari parameter klinis dan radiografis dengan berdasarkan data-data sebagai referensi, antara lain yaitu probing peri-implan, bleeding on probing (BOP), kedalaman probing, supurasi, penilaian radiografis, mobilitas implan. ${ }^{6,7}$

Secara etiopatologi, peri-implantitis sangat mirip dengan penyakit periodontal, keduanya disebabkan akibat invasi oleh bakteri patogen. Pada sulkus implan yang sehat secara klinis, mirip dengan yang ada di gigi normal. Kolonisasi bakteri pada sulkus peri-implan dimulai 30 menit setelah koneksi transmukosal. ${ }^{8}$ Definisi peri-implantitis semakin diperumit oleh banyaknya desain implan, karakteristik permukaan, dan protokol pembedahan dan pembebanan, yang tidak memfasilitasi penentuan yang pasti tentang tingkat kehilangan tulang crestal di sekitar bagian koronal implan yang menandakan remodeling adaptif. dari proses destruktif yang menunjukkan peri implantitis.$^{16,17}$ Perluasan lesi peri-implantitis meluas ke arah apikal dan biasanya berhubungan sizes on each side. Based on the radiograph findings, the diagnosis of peri-implantitis was confirmed.

Conclusion: Peri-implantitis is inflammation around the implant which results in a condition in the form of bone loss around the implant that is placed. Radiographic examination such as CBCT can be an excellent choice to help diagnose peri-implantitis by seeing a clearer 3-dimensional radiograph.
PPDGS Radiologi Kedokteran Gigi, Padjadjaran, Bandung, Indonesia, sitas Padjadjaran, Bandung, Indonesia,

Correspondence to:

曰 indragunawandrg290376@gmail.com

Received on: August 2020 Revised on: September 2020 Accepted on: October 2020 dengan pola keropos tulang yang melingkar. ${ }^{1,12}$ Saat ini, teknik pencitraan 3-dimensi, seperti Cone Beam Computed Tomography (CBCT) dapat meningkatkan penentuan tinggi dan ketebalan tulang, serta mendeteksi struktur anatomi. ${ }^{13-15}$

Banyak literatur membahas fktor rsiko dan prevalensi peri-implantitis, mulai dari microbial biofilm retentive elements yang terkait dengan desain prostesis yang didukung implan, hingga predisposisi sistemik dan paparan lingkungan seperti periodontitis yang sudah ada sebelumnya atau kebiasaan merokok. ${ }^{16,18,19}$ Prevalensi periimplantitis yang dilaporkan oleh beberapa jurnal terdahulu menunjukkan hasil yang sangat bervariasi $^{16,20}$ dan berkisar dari $4 \%$ hingga $45 \% .{ }^{21}$ Prevalensi yang tinggi terjadi pada pasien dengan implan gigi untuk waktu yang lama) ${ }^{22-28}$ dan, ketika terapi yang tepat tidak diberikan, perkembangannya mengikuti pola non-linier dan semakin cepat, sehingga pada akhirnya dapat mengakibatkan kegagalan implan ${ }^{22,29}$

Meskipun strategi pengobatan non-bedah dan bedah sudah dilakukan untuk mengobati periimplantitis, keberhasilannya jarang yang bersifat jangka panjang dan bahkan ketika tercapai, kekambuhan dapat terjadi lagi. ${ }^{30-38}$ Mengingat prediktabilitas yang terbatas ini, pencegahannya menjadi sangat penting. Strategi utama untuk mencegah peri-implantitis adalah pengelolaan mucositis peri-implan ${ }^{39,40}$, karena kondisi ini 
merupakan awal dari keluhan ${ }^{17,41}$

Dalam beberapa literatur juga membahas manfaat CBCT dibandingkan dengan resikonya. Secara umum, ketika manfaat lebih besar daripada risikonya, maka tindakan menggunakan $\mathrm{CBCT}$ dalam mengevaluasi implan dapat dibenarkan ${ }^{42-44}$, misalnya dalam kasus ini adalah untuk memperoleh informasi yang lebih dalam mengenai gambaran radiografis letak dan keparahan peri-implantitis yang dialami pasien.Sejak munculnya CBCT, semakin banyak publikasi ilmiah dalam kaitannya dengan studi tentang CBCT dalam kedokteran gig implan. Tren dan penggunaan CBCT secara proporsional dalam penelitian terkait implan ini sangat sesuai dengan indikasi klinis untuk penggunaan CBCT dalam praktik kedokteran gigi. ${ }^{42}$

Perencanaan perawatan secara digital yang dilakukan terlebih dahulu sebelum melakukan pemasangan implan diharapkan menjadi pendekatan terpadu dari aspek biomekanik, fungsional, dan estetika untuk mengupayakan hasi yang lebih dapat diprediksi, sehingga menghindar terjadinya komplikasi. ${ }^{42,45-47}$ Secara keseluruhan, penempatan implan yang dipandu komputer dapat dianggap akurat, jika dilakukan dengan hati-hati. Kesalahan selama melakukan pencitraan CBCT dan perencanaan perawatan dapat menyebabkan deviasi yang signifikan dan tidak dapat diterima secara klinis. ${ }^{42,46}$

Alasan penggunaan CBCT selama fase perencanaan pra operasi didasarkan pada kebutuhan akan pertimbangan anatomi spesifik (identifikasi batas dan morfologi anatomi, kedekatan struktur anatomi vital), tantangan estetika pada rahang atas anterior, volume tulang yang tidak mencukupi, kualitas tulang, penggunaan teknik bedah yang terbaru (grafting, distraksi, implan zygomatik) dan perencanaan prabedah terintegrasi dan pendekatan kepada pasien secara virtual. ${ }^{43-45,47-51}$

Pada dasarnya perawatan implan gig meliputi pembersihan profesional oleh dokter gig dan perawatan mulut di rumah oleh pasien itu sendiri. Kebersihan mulut yang baik di pihak pasien adalah wajib. Posisi dan desain protesa yang sulit diatur dapat membatasi keefektifan pembersihan mekanis. Pasien harus dipanggil kembali setiap 3 bulan selama tahun pertama dan setidaknya setiap 6 bulan setelahnya. Implan gigi harus dirawat lebih intensif dalam perawatannya daripada gigi asli, karena kurangnya organized fibers di jaringan lunak yang mengelilingi implan mengakibatkan peningkatan risiko kerusakan yang disebabkan oleh bakteri patogen diantara implan gigi dan tulang ${ }^{52}$

Adapun kondisi pasien saat ini mengalami keluhan berupa rasa tidak nyaman pada area yang dipasangkan implan. Tujuan dari laporan kasus ini adalah memberikan gambaran tentang adanya periimplantitis pada tulang di sekitar implant yang sudah terpasang pada radiograf CBCT.

\section{LAPORAN KASUS}

Seorang pria berusia 61 tahun dirujuk ke instalasi radiologi kedokteran gigi untuk dilakukan pemerikasaan CBCT. Pasien mengeluhkan rasa sakit pada area gigi yang dipasangkan implan. Penilaian dilakukan dengan melihat kondisi implan dan jaringan sekitarnya dari pandangan secara 3 dimensi secara coronal, sagittal dan axial. Hasil pemeriksaan CBCT menunjukkan terdapat peradangan di sekitar implan yang telah terpasang, ditandai dengan tampaknya gambaran area radiolusen di $1 / 3$ servikal implan pada sisi mesial, distal, bukal/labial dan palatalnya dengan ukuran yang bervariasi di masing-masing sisi. Berdasarkan temuan radiograf ditegakkan diagnosis periimplantitis, dimana tampak gambaran radiolusen pada sekitar implan yang dipasangkan yang menandakan tidak terjadinya osseointegration dengan baik antara implan dengan tulang di sekitarnya.

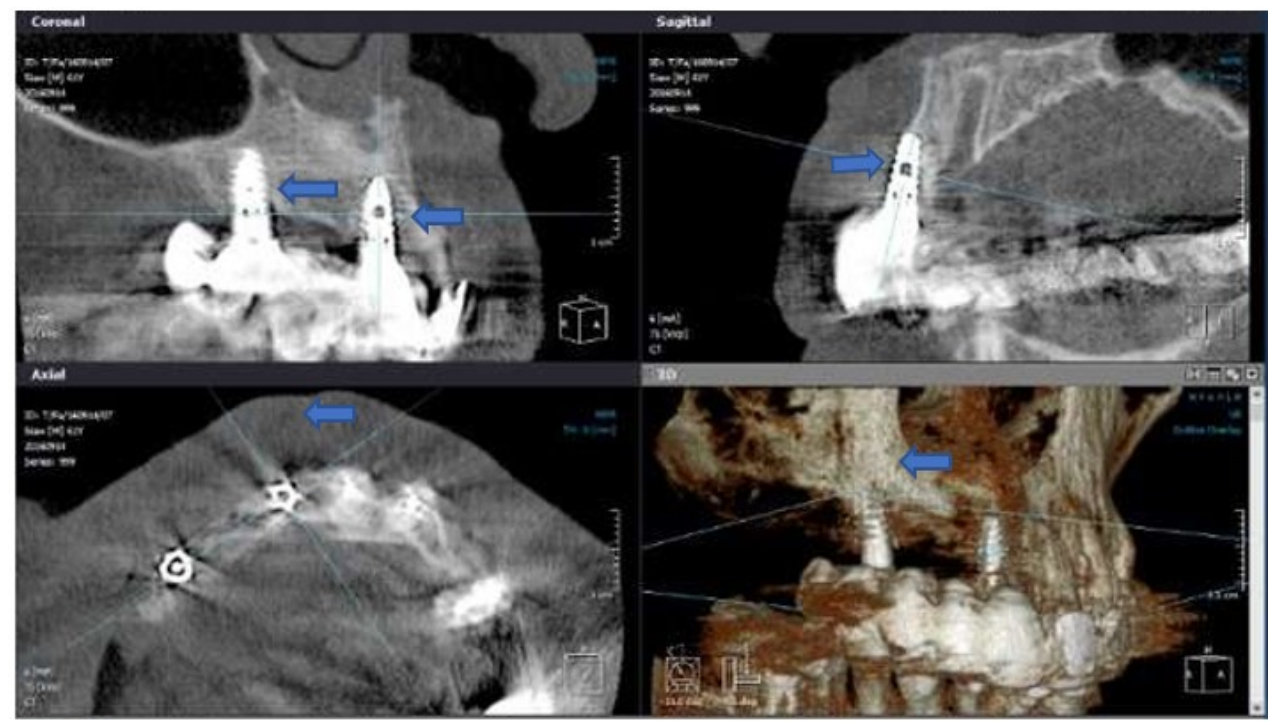

Gambar 1. MPR view regio 11-13. Lokasi peri-implantitis. Coronal view menunjukkan lokasi pada mesial implan gigi 11 dan 13 (atas kiri). Sagital view menunjukkan lokasi pada labial implan gigi 11 (kanan atas). Axial view menunjukkan lokasi pada labial implan gigi 11 (kiri bawah). 3D view menunjukkan lokasi pada mesial implan gigi 13 (kanan bawah) 


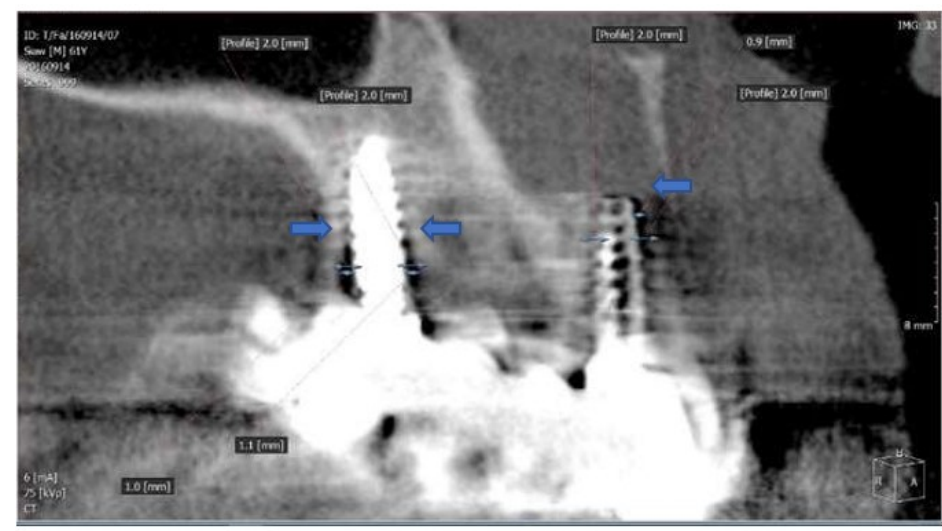

Gambar 2. Coronal view slice ke-33

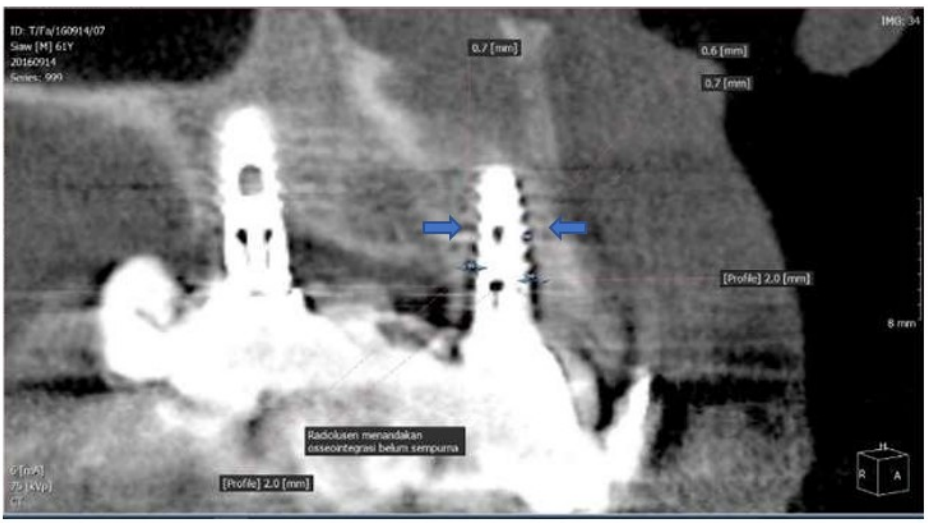

Gambar 3. Coronal view slice ke-34

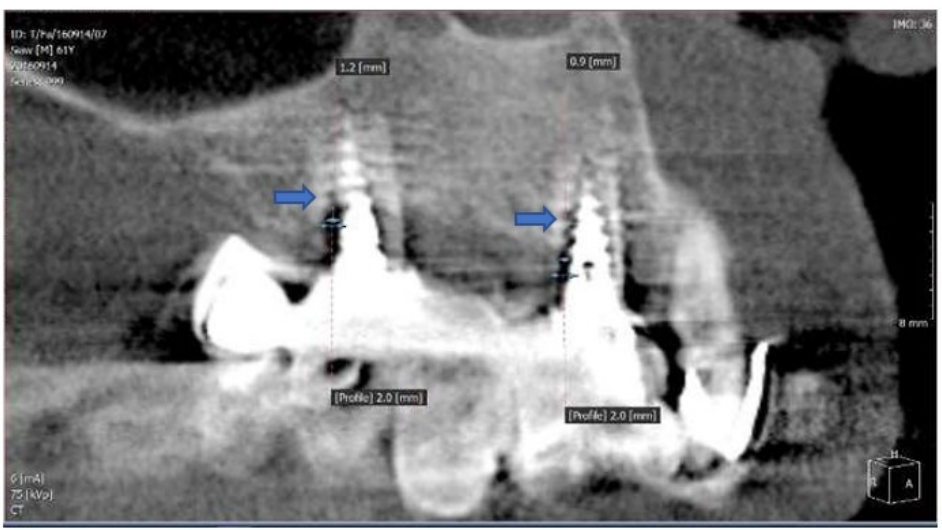

Gambar 4. Coronal view slice ke-36

Hasil pemeriksaan yang didapatkan dari terlihat gambaran area radiolusen di distal dari $1 / 3$ pemeriksaan $\mathrm{CBCT}$, menunjukkan adanya keadaan servikal implan dengan jarak sekitar $0,9 \mathrm{~mm}$ pada yang tidak normal berupa gambaran radiolusen implan gigi 11 dan terlihat gambaran area diantara implan yang telah dipasang dengan tulang radiolusen di distal dari 1/3 servikal implan dengan di sekitar implan gigi (Gambar 1).

Pada pemeriksaan coronal view slice ke-33, 4).

terlihat gambaran area radiolusen di mesial dari $1 / 3$ Pada pemeriksaan sagital view slice ke-48 apikal implan dengan jarak sekitar $0,9 \mathrm{~mm}$ pada terlihat gambaran area radiolusen di labial dari $1 / 3$ implan gigi 11 dan terlihat gambaran area servikal implan dengan jarak sekitar 0,6 mm pada radiolusen di mesial dan distal dari $1 / 3$ servikal implan gigi 11 (Gambar 5).

implan dengan jarak sekitar 1,1 $\mathrm{mm}$ dan $1 \mathrm{~mm}$ pada implan ggi 13 (Gambar 2).

Pada pemeriksaan sagital view slice ke-63

Pada pemeriksaan coronal view slice ke-34 palatal dari $1 / 3$ servikal implan dengan jarak sekitar terlihat gambaran area radiolusen di mesial dan $0,8 \mathrm{~mm}$ dan 0,7 $\mathrm{mm}$ (Gambar 6).

distal dari $2 / 3$ servikal implan dengan jarak ratarata $0,65 \mathrm{~mm}$ pada implan gigi 11 (Gambar 3 ).

Pada pemeriksaan axial view slices, pada slice ke-23 dan ke-26 terlihat jelas gambaran area Pada pemeriksaan coronal view slice ke-36 radiolusen di sekitar implan 11 dan 13 (Gambar 7). 


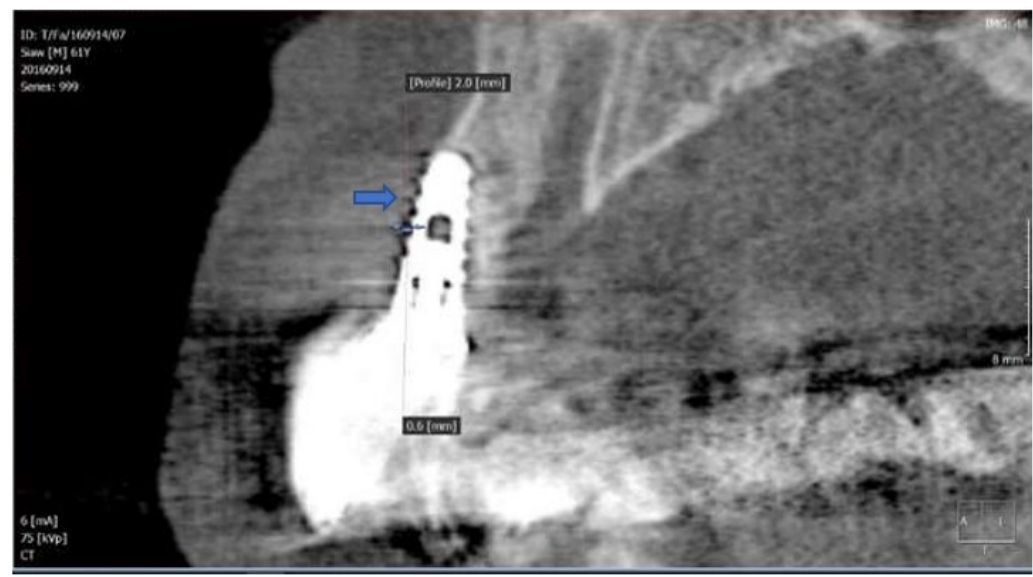

Gambar 5. Sagital view slice ke-48 regio implan 11

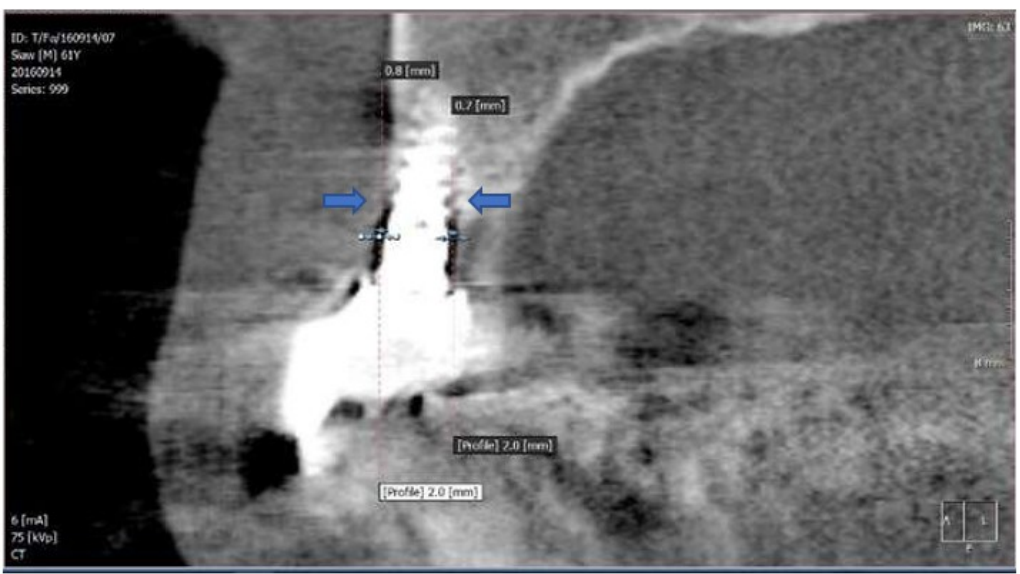

Gambar 6. Sagital view slice ke-63 regio implan 13

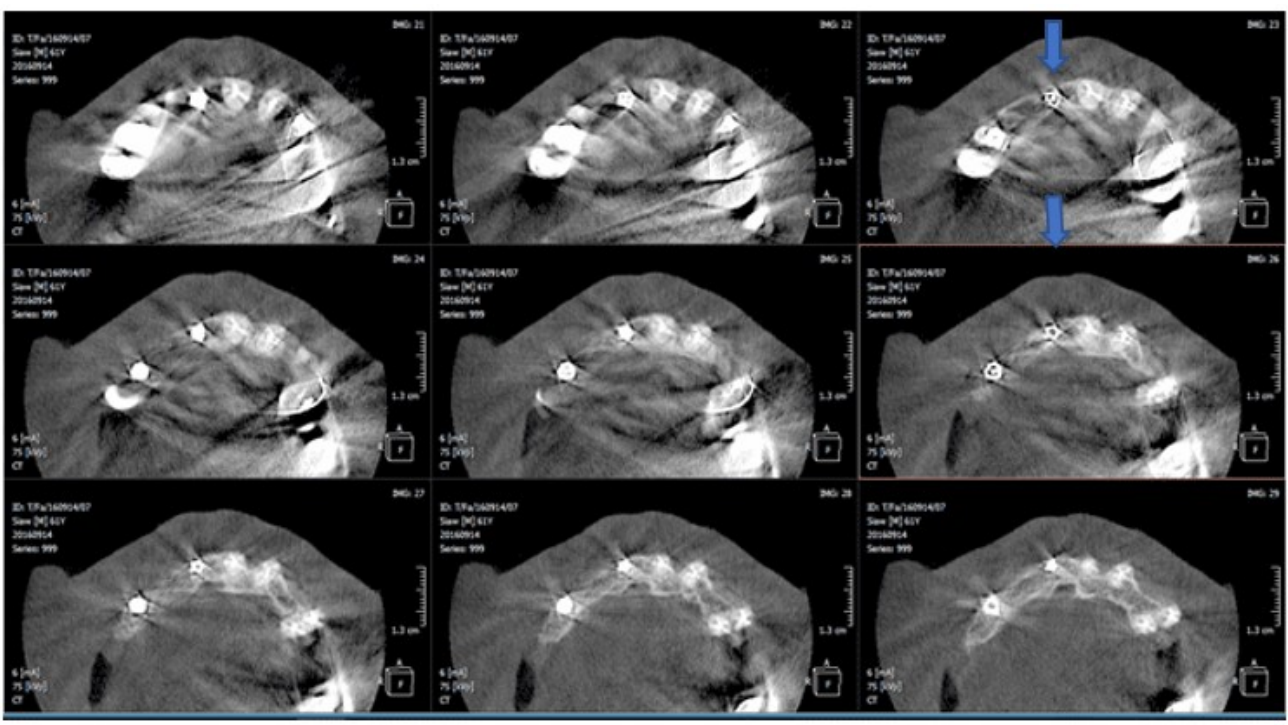

Gambar 7. Axial view slices

\section{DISKUSI}

Penyakit peri-implan diklasifikasikan menjadi dua jenis: peri-implan mucositis (seperti gingivitis) dan peri-implantitis (mirip dengan periodontitis). ${ }^{57,58}$ Definisi kedua penyakit ini pertama kali diusulkan pada 1st European Workshop on Periodontology (EWOP). ${ }^{59}$ Periimplantitis dianggap sebagai proses inflamasi yang terkait dengan hilangnya tulang pendukung di sekitar implan yang berfungsi, yang umumnya ditandai dengan adanya resorpsi tulang, purulensi, penurunan osseointegrasi implan, dan adanya pembentukan poket. ${ }^{57,58,60}$ Mucositis peri-implan adalah proses inflamasi reversibel yang terbatas pada jaringan lunak saja. Ini dapat menyebabkan hilangnya implan jika tidak didiagnosis dengan benar atau tidak dikelola dengan baik. ${ }^{61}$ Mucositis 


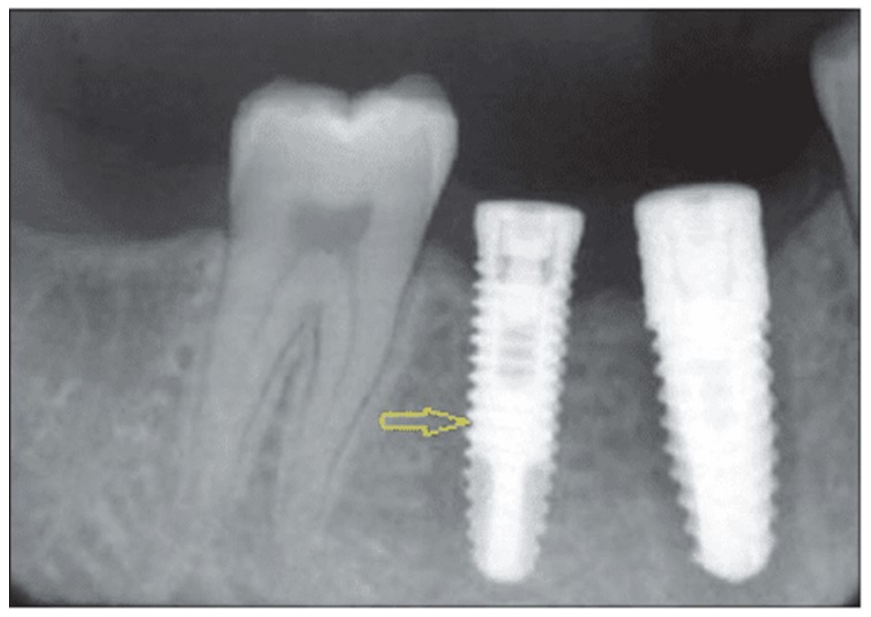

Gambar 8, Radiograf pada regio posterior rahang bawah yang menunjukkan adanya osseointegrasi implan gigi dengan tulang yang baik (panah). ${ }^{54}$

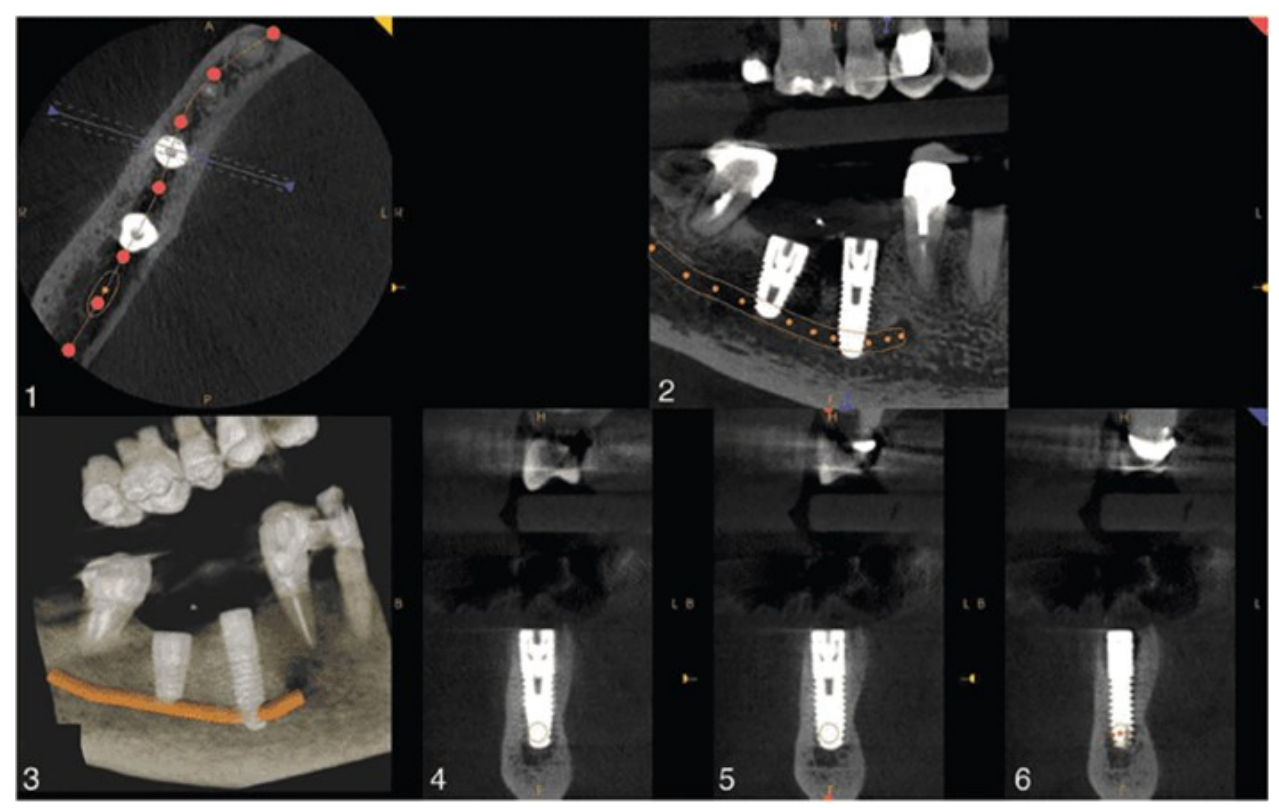

Gambar 9. Radiograf CBCT yang menggambarkan 2 implan di sisi kanan mandibula yang telah menembus dan melewati saluran saraf. ${ }^{55}$
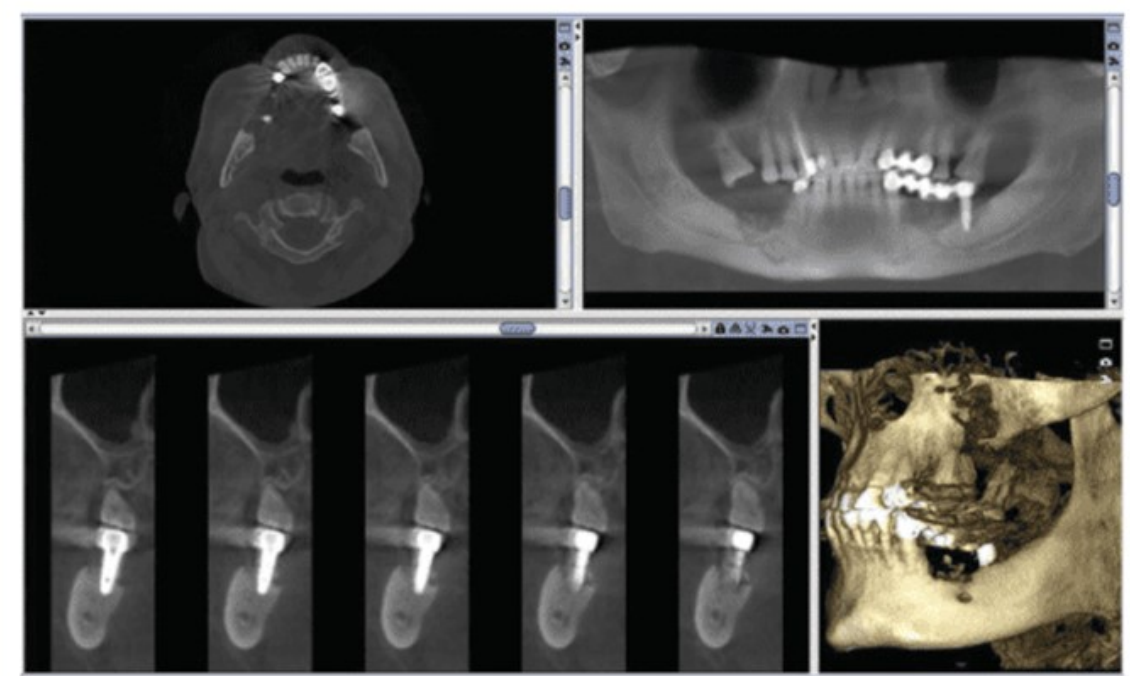

Gambar 10. Radiograf CBCT kasus peri-implantitis yang menunjukkan resorpsi tulang di sekitar implan gigi. ${ }^{56}$ 
peri-implan ditandai dengan tanda-tanda khas peradangan jaringan lunak seperti kemerahan, pembengkakan, dan perdarahan pada pemeriksaan periodontal. ${ }^{62,63}$

Berbagai studi dilakukan membahas tentang kegagalan implan gigi dan bagaimana mencegah kegagalan tersebut. Kegagalan implan memiliki dimensi multifaktor. Seringkali banyak faktor yang berkolaborasi menyebabkan kegagalan akhi sebuah implan gigi. Perlu untuk mengetahui penyebab kegagalan, sebagai pengalaman untuk perawatan di masa mendatang. Pengumpulan data yang tepat, respon pasien, dan alat diagnostik yang akurat akan membantu menunjukkan alasan kegagalan. Perawatan dini bisa mungkin dilakukan jika dilakukan pemeriksaan secara rutin. Berbaga kriteria telah diusulkan untuk evaluasi keberhasilan implan. Kriteria yang menentukan keberhasilan implan gigi terus berubah, termasuk diantaranya adalah tidak adanya mobilitas pada awal fase prostetik, tidak adanya radiolusen berkelanjutan $\mathrm{d}$ sekitar implan, tidak adanya peri-implantitis dengan supurasi, dan keluhan subjektif dari pasien. ${ }^{53}$

Keberhasilan implan gigi dilakukan dengan cara mengevaluasi secara rutin, dibutuhkan bantuan radiograf foto untuk melihat beberapa keadaan seperti adanya osseointegrasi implan gigi dengan tulang (Gambar 8) ${ }^{54}$, apakah implan gigi telah menembus dan melewati saluran saraf (Gambar 9) 55 , atau untuk melihat kasus peri-implantitis yang menunjukkan resorpsi tulang di sekitar implan gig (Gambar 10$)^{56}$, sehingga didapatkan gambaran yang jelas tentang keberhasilan atau kegagalan dari implan gigi yang dipasangkan.

Beberapa faktor sistemik yang dapat mempengaruhi terjadinya peri-implantitis, antara lain:

Riwayat periodontitis. Beberapa jurnal menunjukkan, meskipun tingkat keawetan implan mungkin tidak akan terpengaruh oleh riwayat penyakit periodontal, namun demikian, periimplantitis lebih sering didapati pada pasien dengan riwayat periodontitis; ${ }^{8,10}$

Kebiasaan merokok. Satu studi melaporkan, 78\% dari implan yang dipasangkan pada pasien perokok mengalami peri-implantitis, sedangkan untuk non-perokok hanya $64 \%{ }^{8,10}$

Diabetes. Kadar glukosa darah tingg mempengaruhi perbaikan jaringan dan mekanisme pertahanan host, kontrol diabetes mempengaruhi fungsi neutrofil sehingga diabetes dapat mengganggu homeostasis kolagen dalam matriks ekstrasel dan berkorelasi dengan disfungsi neutrofil serta ketidakseimbangan sistem kekebalan tubuh Maka, kemampuan perbaikan jaringan dan mekanisme pertahanan pasien diabetes untuk melawan plak menjadi terganggu. ${ }^{8,10}$

Genetik. Interleukin memainkan peran penting dalam proses peradangan. Hubungan interleukin-1 (IL-1) dengan periodontitis juga telah dikaitkan dengan peri-implantitis dan sinergis dengan merokok. Hubungan ini masih diperdebatkan karena tidak semua penelitian mendukung ini.
Karena itu, pengujian genetik rutin tidak dianjurkan untuk pasien implan pada saat ini. ${ }^{8,9}$

Selain faktor sistemik, terdapat beberapa faktor risiko lokal yang mempunyai pengaruh pada terjadinya peri-implantitis seperti:

Oral hygiene $(\mathrm{OH})$ yang buruk. $\mathrm{OH}$ yang buruk dapat meningkatkan risiko peri-implantitis 2,5 kali lebih besar, karena plak pada suprastruktur implan mengakibatkan terjadinya peri-implan mukosistis yang berkembang menjadi peri-implantitis; ${ }^{8,9}$

Sisa semen. Sisa sementasi mahkota pada implan, karena posisi dan desain yang kurang tepat, memungkinkan terjadinya kelebihan semen yang tidak dapat dibersihkan sehingga menghambat upaya terapi non-bedah mekanik untuk mengakses ruang subgingiva. Selain itu, ada beberapa semen yang sering digunakan tidak terdeteksi oleh survei radiograf. Semen tersebut dapat menyebabkan peradangan akibat dari kekasaran permukaan yang dapat memberikan lingkungan yang positif untuk perlekatan bakteri;

Beban oklusal. Implan dianggap kurang dapat menoleransi beban oklusal non-aksial dibandingkan dengan gigi karena kurangnya keberadaan ligamen periodontal. Beberapa penelitian menunjukkan bahwa beban oklusal terkonsentrasi di tulang marginal implan. Remodeling tulang dalam menanggapi ketegangan yang berlebihan dapat menyebabkan mikrofraktur pada tulang dan akhirnya terjadi kehilangan tulang; ${ }^{8,10}$

Permukaan implan. Permukaan implan umumnya diklasifikasikan atas empat kategori tergantung pada nilai kekasaran permukaan, yaitu halus, sedikit kasar, cukup kasar atau kasar. Umumnya implan yang dipasarkan saat ini memiliki permukaan cukup kasar, yang optimal untuk respon penyembuhan. Permukaan implan mempengaruhi retensi biofilm dan implan dengan permukaan yang sangat kasar, seperti titanium plasma sprayed (TPS) surface dan hydroxyapatite (HA) coated surface meningkatkan kemungkinan peri-implantitis; ${ }^{8,9}$

Lebar dari attached gingival. Meskipun kelangsungan implan tercatat tidak berbeda secara signifikan antara nonkeratinized dan keratinized mukosa peri-implan, perlu dicatat bahwa beberapa penelitian melakukan pencatatan bahwa mukositis dan kerusakan tulang pada implan di mukosa nonkeratinized lebih tinggi ketika kontrol plak tidak adekuat. ${ }^{8,11}$

Perawatan bedah biasanya diperlukan untuk mengobati peri-implantitis sedangkan hanya terapi non-bedah yang dapat digunakan untuk mengobati mucositis peri-implan. Setidaknya diperlukan 12 bulan untuk mengevaluasi efek pasca perawatan bedah. ${ }^{64}$ Pada satu studi tentang efek jangka pendek pengobatan bedah periimplantitis, menunjukkan bahwa peradangan berkurang dengan operasi peri implantitis resektif tetapi perdarahan saat probing / supurasi masih ada yang membutuhkan evaluasi dan pemeliharaan jangka panjang. ${ }^{65}$ 


\section{SIMPULAN}

Peri-implantitis merupakan peradangan $\mathrm{di}$ sekitar implan yang mengakibatkan keadaan berupa terjadinya kehilangan tulang di sekitar implan gigi yang dipasangkan. Pemeriksaan radiografi seperti $\mathrm{CBCT}$, dan tentunya diawali dengan pemeriksaan secara klinis yang baik juga, dapat menjadi pilihan yang sangat baik untuk membantu penegakkan diagnosis Peri-implantitis dengan melihat gambaran yang lebih jelas secara radiografis 3 dimensi.

\section{DAFTAR PUSTAKA}

1. Schwarz F, Derks J, Monje A, Wang H-L. Peri-implantitis. J Clin Periodontol. 2018;45(June 2016):S246-66.

2. Berglundh T, Armitage G, Araujo MG, Avila-Ortiz G, Blanco J, Camargo PM,et al. Peri-implan diseases and conditions: consensus report of workgroup 4 of the 2017 World Workshop on the classification of periodontal and periimplan diseases and conditions. J Clin Periodontol [Internet]. 2018 [cited 2018 Nov 19];45:S286-S291. Available from: http:// www.ncbi.nlm.nih.gov/pubmed/29926491.

3. Dalago HR, Schuldt Filho G, Rodrigues MAP, Renvert $S$, Bianchini MA. Risk indicators for peri-implantitis. A cross sectional study with 916 implans. Clin Oral Implans Res [Internet]. 2016 Jan [cited 2016 Jul 15];n/a-n/a. Available from: http://doi.wiley.com/10.1111/clr.12772.

4. Bianchini MA, Galarraga-Vinueza ME, Apaza-Bedoya K, De Souza JM, Magini R, Schwarz F. Two to six-year disease resolution and marginal bone stability rates of a modified resective-implanoplasty therapy in 32 peri-implantitis cases. Clin Implan Dent Relat Res [Internet]. 2019 [cited 2019 Aug 8];cid. 12773. Available from: http://www.ncbi.nlm.nih.gov/ pubmed/30985073.

5. Galárraga-Vinueza et al. Histological characteristics of advanced peri-implantitis bone defects in humans. International Journal of Implan Dentistry (2020) 6:12

6. Billy Martin, Robert Lessang. Peri-implantitis: definisi, diagnosis, etiologi dan manajemen penatalaksanaanya. Makassar Dent J 2015; 4(4): 107-113 ISSN:2089-8134 107

7. Bianca Di Murro, Piero Papi, Pier Carmine Passarelli, Antonio D’Addona and Giorgio Pompa. Attitude in Radiographic Post Operative Assessment of Dental Implans among Italian Dentists: A Cross-Sectional Survey. Antibiotics 2020, 9, 234 doi:10.3390/antibiotics9050234

8. Furst MM, Salvi GE, Lang NP, Persson G. Bacterial colonization immediately after installation on oral titanium implans. Clin Oral Implans Res 2007;18:501-8

9. Karnik R, Pradhan S. Peri-implan diseaase-- a clinical overview (Part 1): diagnosis, etiopathology and risk-related aspects. Int J Laser Dent 2012;2(1):18-25

10. Rosen $P$, Clem D, Cochran D, Froum S, McAllister B, Renvert S, et al. Peri-Implan Mucositis and peri-implantitis: a current understanding of their diagnoses and clinical implications. J Periodontol 2013;84(4):436-43

11. Todescan S, Lavigne S, Kelekis-Cholakis A. Guidance for the maintenance care of dental implans: clinical review. J Can Dent Assoc 2012;78:c107

12. Karnik R, Pradhan S. Peri-implan diseaase-- a clinical overview (Part 1): diagnosis, etiopathology and risk-related aspects. In J Laser Dent 2012;2(1):18-25

13. Derks J, Schaller D, Håkansson J, Wennström JL, Tomasi C, Berglundh T. Periimplantitis - onset and pattern of progression. J Clin Periodontol [Internet]. 2016 [cited 2019 Mar 13];43(4):383-388. Available from: http://doi.wiley. com/10.1111/jcpe.12535.

14. De Bruin, H.; Vandeweghe, S.; Ruy elaert, C.; Cosyn, J. Sennerby, L. Radiographic evaluation of modern oral implans with emphasis on crestal bone level and relevance to periimplan health. Periodontol 2000. 2013, 62, 256-270. [CrossRef]

15. Omami, G. Cone-Beam Computed Tomography in Implan Dentistry: Back to the Future. J. Oral. Maxillofac. Surg. 2017, 75, 655. [CrossRef]

16. Khashayar Kordbacheh Changi, Joseph Finkelstein, Panos N Papapanou. Peri-implantitis prevalence, incidence rate, and risk factors: A study of electronic health records at a U.S dental school. Clin Oral Impl Res. 2019;30:306-314.

17. Berglundh, Armitage, Avila - Ortiz, et al. Consensus report: Peri-implan diseases and conditions. Journal of Periodontology, 2018, 89, 1-6. https:// doi.org/10.1002/ JPER.17-0739

18. Heitz-Mayfield, L. J., \& Huynh-Ba, G. History of treated periodontitis and smoking as risks for implan therapy. International Journal of Oral and Maxillofacial Implans, 2009, 24 (Suppl), 39-68.

19. Saaby, M., Karring, E., Schou, S., \& Isidor, F. Factors influencing severity of peri-implantitis. Clinical Oral Implans Research, 2016, 27, 7-12. https://doi.org/10.1111/clr.12505

20. Atieh, M. A., Alsabeeha, N. H., Faggion, C. M. Jr, \& Duncan, W. J. The frequency of peri-implan diseases: A systematic review and meta-analysis. Journal of Periodontology, 2013, 84, 15861598. https://doi.org/10.1902/jop.2012.120592.

21. Derks, J. Effectiveness of implan therapy in Sweden. Dr. Odont. thesis, Institute of Odontology, Sahlgrenska Academy (pp. 1-89). Gothenburg, Sweden: University of Gothenburg. 2015.

22. Mario Romandini1; Cristina Lima1; Ignacio Pedrinaci1; Ana Araoz1; Maria Costanza Soldini; Mariano Sanz. Prevalence and risk/protective indicators of peri-implan diseases: a universityrepresentative cross-sectional study. 2020. https:// doi.org/10.1101/2020.06.04.20121970

23. Derks, J., \& Tomasi, C. Peri-implan health and disease. A systematic review of current epidemiology. J Clin Periodontol. 2015, 42 Suppl 16, , S158-71. http://doi.org/10.1111/ jcpe.12334

24. Derks, J., Schaller, D., Hakansson, J., Wennstrom, J. L., Tomasi, C., \& Berglundh, T. Effectiveness of Implan Therapy Analyzed in a Swedish Population: Prevalence of Peri-implantitis. J Dent Res. 2016a, 95(1), 43-49. http:// doi.org/10.1177/0022034515608832.

25. Rakic, M., Galindo Moreno, P., Monje, A., Radovanovic, S. Wang, H.-L., Cochran, D., et al. How frequent does periimplantitis occur? A systematic review and meta-analysis. Clinical Oral Investigations. 2018, 22(4), 1805-1816. http:// doi.org/10.1007/s00784-017-2276.

26. Romandini, M., Cordaro, M., Donno, S., \& Cordaro, L. Discrepancy between patient satisfaction and biologic complication rate in patients rehabilitated with overdentures and not participating in a structured maintenance program after 7 to 12 years of loading. The International Journal of Oral \& Maxillofacial Implans. 2019, 34(5), 1143-1151. http:// doi.org/10.11607/jomi.74652019

27. Vignoletti, F., Di Domenico, G. L., Di Martino, M., Montero, E. \& De Sanctis, M. Prevalence and risk indicators of periimplantitis in a sample of university-based dental patients in Italy: A cross-sectional study. J Clin Periodontol. 2019, 46 (5), 597-605. http://doi.org/10.1111/jcpe.13111

28. Wada, M., Mameno, T., Onodera, Y., Matsuda, H., Daimon, K. \& Ikebe, K. Prevalence of peri-implan disease and risk indicators in a Japanese population with at least 3 years in function-A multicentre retrospective study. Clinical Oral Implans Research. 2019, 30(2), 111-120. http:// doi.org/10.1111/clr.13397

29. Derks, J., Schaller, D., Håkansson, J., Wennström, J. L., Tomasi, C., \& Berglundh, T. Peri-implantitis - onset and pattern of progression. J Clin Periodontol. 2016b, 43(4), 383-388. http:// doi.org/10.1111/jcpe.12535

30. Berglundh, T., Wennström, J. L., \& Lindhe, J. Long-term outcome of surgical treatment of peri-implantitis. A 2-11-year retrospective study. Clinical Oral Implans Research. 2018b, 29 (4), 404-410.

31. Carcuac, O., Derks, J., Abrahamsson, I., Wennström, J. L., Petzold, M., \& Berglundh, T. Surgical treatment of periimplantitis: 3-year results from a randomized controlled clinical trial. J Clin Periodontol. 2017, 44(12), 1294-1303. http://doi.org/10.1111/jcpe.12813

32. Cha, J. K., Lee, J. S., \& Kim, C. S. Surgical Therapy of PeriImplantitis with Local Minocycline: A 6-Month Randomized Controlled Clinical Trial. J Dent Res. 2019, 98(3), 288-295. http://doi.org/10.1177/0022034518818479

33. de Tapia, B., Valles, C., Ribeiro-Amaral, T, Mor, C., Herrera, D., Sanz, M., \& Nart, J. The adjunctive effect of a titanium brush in implan surface decontamination at peri-implantitis surgical regenerative interventions: A randomized controlled clinical trial. J Clin Periodontol. 2019, 46(5), 586-596. http:// doi.org/10.1111/jcpe.13095

34. Figuero, E., Graziani, F., Sanz, I., Herrera, D., \& Sanz, M. Management of peri-implan mucositis and peri-implantitis. Periodontol 2000. 2014, 66(1), 255-273. http:// 
doi.org/10.1111/prd.12049

35. Heitz-Mayfield, L. J. A., \& Salvi, G. E. Peri-implan mucositis. Clin Periodontol. 2018, 45 Suppl 20, S237-S245. http:// doi.org/10.1111/jcpe.12953

36. Nart, J., Pons, R., Valles, C., Esmatges, A., Sanz-Martín, I., \& Monje, A. (2020). Non-surgical therapeutic outcomes of periimplantitis: 12-month results. Clinical Oral Investigations, 24 (2), 675-682. http://doi.org/10.1007/s00784-019-02943-8

37. Ravidà, A., Saleh, I., Siqueira, R., Garaicoa-Pazmiño, C., Saleh, M. H. A., Monje, A., \& Wang, H.-L. Influence of keratinized mucosa on the surgical therapeutical outcomes of periimplantitis. J Clin Periodontol. 2020b, 47(4), 529-539. http:// doi.org/10.1111/jcpe.13250

38. Roccuzzo, M., Layton, D. M., Roccuzzo, A., \& Heitz-Mayfield, L. J. Clinical outcomes of peri-implantitis treatment and supportive care: A systematic review. Clinical Oral Implans Research. 2018, 29 Suppl 16, 331-350. http:// doi.org/10.1111/clr.13287

39. Barootchi, S., Ravidà, A., Tavelli, L., \& Wang, H. -L. Nonsurgical treatment for peri-implan mucositis: A systematic review and meta-analysis. International Journal of Oral Implanology (New Malden, London, England). 2020, 13(2), 123-139.

40. Jepsen, S., Berglundh, T., Genco, R., Aass, A. M., Demirel, K., Derks, J., et al. Primary prevention of peri-implantitis: managing peri-implan mucositis. J Clin Periodontol. 2015, 42 Suppl 16, S152-7. http://doi.org/10.1111/jcpe.12369

41. Costa, F. O., Takenaka-Martinez, S., Cota, L. O. M., Ferreira, S. D., Silva, G. L. M., \& Costa, J. E. (2012). Peri-implan disease in subjects with and without preventive maintenance: a 5-year follow-up. J Clin Periodontol, 39(2), 173-181. http:// doi.org/10.1111/j.1600-051X.2011.01819

42. Reinhilde Jacobs, Benjamin Salmon, Marina Codari, Bassam Hassan and Michael M. Bornstein. Cone beam computed tomography in implan dentistry: recommendations for clinical use. BMC Oral Health 2018 18:88. https://doi.org/10.1186/ s12903-018-0523-5

43. Bornstein MM, Scarfe WC, Vaughn VM, Jacobs R. Cone beam computed tomography in implan dentistry: a systematic review focusing on guidelines, indications, and radiation dose risks. Int J Oral Maxillofac Implans. 2014;29(Suppl):55-77.

44. Harris D, Horner K, Gröndahl K, Jacobs R, Helmrot E, Benic GI, Bornstein MM, Dawood A, Quirynen M. Guidelines for the use of diagnostic imaging in implan dentistry 2011: update of the E.A.O. A consensus workshop organized by the European Association for Osseointegration in the Medical University of Warsaw, Poland. Clin Oral Implans Res. 2012; 23: 1243-53.

45. Van Assche N, van Steenberghe D, Quirynen M, Jacobs R. Accuracy assessment of computer-assisted flapless implan placement in partial edentulism. J Clin Periodontol. 2010; 37:398-403.

46. Van Assche N, Vercruyssen M, Coucke W, Teughels W, Jacobs $R$, Quirynen M. Accuracy of computer-aided implan placement. Clin Oral Implans Res. 2012; 23: 112-23.

47. Vercruyssen M, Laleman I, Jacobs R, Quirynen M. Computersupported implan planning and guided surgery: a narrative review. Clin Oral Implans Res. 2015;26(Suppl): 69-76.

48. Jacobs R, Quirynen M. Dental cone beam computed tomography: justification for use in planning oral implan placement. Periodontology 2000. 2014; 66: 203-13

49. Tyndall DA, Price JB, Tetradis S, Ganz SD, Hildebolt C, Scarf WC, American Academy of Oral and Maxillofacial Radiology. Position statement of the American Academy of oral and maxillofacial radiology on selection criteria for the use of radiology in dental implanology with emphasis on cone beam computed tomography. Oral Surg Oral Med Oral Pathol Oral Radiol. 2012;113:817-26.

50. van Steenberghe D, Malevez C, Van Cleynenbreugel J, Bou Serhal C, Dhoore E, Schutyser F, Suetens P, Jacobs R. Accuracy of drilling guides for transfer from three-dimensional CTbased planning to placement of zygoma implans in human cadavers. Clin Oral Implans Res. 2003; 14: 131-6.

51. Joda T, Brägger U, Gallucci G. Systematic literature review of digital threedimensional superimposition techniques to create virtual dental patients. Int J Oral Maxillofac Implans. 2015; 30 330-7.

52. Dr. Hema Kanathila, Dr. Ashwin Pangi, Dr. Veena Benakatti and Dr. Suvidha Patil. Maintenance of dental implans: A way to long term success: A review. International Journal of Applied Dental Sciences. 2018; 4(2): 104-107.

53. Dr. Resham Maheshwari, Dr. Vikas Punia, Dr. Meenaksh Khandelwal, Dr. Vivek Sharma, Dr. Saransh Malot and Dr. Anand Porwal. Implan failure and management: A review International Journal of Applied Dental Sciences 2018; 4(2): 293-298
54. Aishwarya Nagarajan, Rajapriya Perumalsamy, Ramakrishnan Thyagarajan, Ambalavanan Namasivayam. Diagnostic Imaging for Dental Implan Therapy. Journal of Clinical Imaging Science. 2016, Vol. 4

55. Jonathan Du Toit, BChD, MSc Dent, Howard Gluckman, BDS, MChD, Rami Gamil, BDS, Tara Renton, BDS, MDSc, PhD. Implan Injury Case Series and Review of the Literature. Journal of Oral Implanology. 2015, Vol. XLI. DOI: 10.1563/ AAID-JOI-D-14-00022

56. Ufuk Tatli and Burcu Evlice. Cone-Beam Computed Tomography for Oral and Maxillofacial Imaging. 2017. http:// dx.doi.org/10.5772/intechopen.69282

57. Wilson V. An insight into peri-implantitis: a systematic literature review. Primary dental journal. Apr 2013;2(2):69-73.

58. Khammissa RA, Feller L, Meyerov R, Lemmer J. Peri-implan mucositis and peri-implantitis: clinical and histopathological characteristics and treatment. SADJ: journal of the South African Dental Association = tydskrif van die Suid-Afrikaanse Tandheelkundige Vereniging. Apr 2012;67(3):122, 124-126.

59. Zitzmann NU, Berglundh T. Definition and prevalence of periimplan diseases. Journal of clinical periodontology. Sep 2008:35(8 Suppl):286-291.

60. Smeets R, Henningsen A, Jung $O$, Heiland $M$, Hammacher $C$ Stein JM. Definition, etiology, prevention and treatment of peri-implantitis--a review. Head \& face medicine. Sep 32014 10: 34 .

61. Mombelli A, Muller N, Cionca N. The epidemiology of periimplantitis. Clinical oral implans research. Oct 2012;23 Suppl 6:67-76

62. Burt B. Position paper: epidemiology of periodontal diseases. Journal of periodontology. Aug 2005;76(8):1406-1419.

63. Savage A, Eaton KA, Moles DR, Needleman I. A systematic review of definitions of periodontitis and methods that have been used to identify this disease. Journal of clinical periodontology. Jun 2009;36(6):458-467.

64. Sanz M, Chapple IL, Working Group 4 of the VIII European Workshop on Periodontology*. Clinical research on periimplan diseases: consensus report of $\mathrm{W}$ orking $\mathrm{G}$ roup 4 . Journal of clinical periodontology. 2012;39:202-6

65. Koldsland OC, Wohlfahrt JC, Aass AM. Surgical treatment of peri-implantitis: Prognostic indicators of short-term results. Journal of clinical periodontology. 2018;45(1):100-13. 